\title{
Evaluating Civic Open Data Standards
}

\author{
Renee Sieber, McGill University and Rachel Bloom, Open North
}

\begin{abstract}
:
In many ways, a precondition to realizing the promise of open government data is the standardization of that data. Open data standards ensure interoperability, establish benchmarks in assessing whether governments achieve their goals in publishing open data, can better ensure accuracy of the data. Interoperability enables the use of off-the shelf software and can ease third party development of products that serves multiple locales. Our project aims to determine which standards for civic data are "best" to open up government data. We began by disambiguating the multiple meanings of what constitutes a data standard by creating a standards stack. The empirical research started by identifying twelve "high value" open datasets for which we found 22 data standards. A qualitative systematic review of the gray literature and standards documentation generated 18 evaluation metrics, which we grouped into four categories. We evaluated the metrics with civic data standards. Our goal is to identify and characterize types of standards and provide a systematic way to assess their quality.
\end{abstract}

\section{Introduction}

In 2005, Bibiana McHugh, the IT manager at Portland, Oregon's Trimet public transit agency, was frustrated that the general public could not easily access public transit information (McHugh, 2013). She wanted transit directions to be as open in trip planning as driving directions provided by platforms such as Google Maps and Mapquest. Since Trimet's transit database was complex, she needed a way to publish the data in a format that lowered barriers for accessing and repurposing the data.

The result of these efforts was an open data standard, called the Google Transit Feed Specification. GTFS, which later became the General Transit Feed Specification, was a relatively easy to consume standard for transit information. Trimet provided the "raw" data and Google provided the script to export the data into the structured GTFS schema. In December of 2005, Google utilized GTFS to launch Google Transit, a free online trip-planning feature for the Portland Metro area. By 2012, an estimated 262 agencies around the world shared their GTFS data online with the public (Antrim \& Barbeau, 2013). By 2017, over 6,000 agencies were using GTFS worldwide (http://maps.google.com/landing/transit/cities/index.html).

GTFS exemplifies why standards have become crucial in opening up government data. According to the Open Knowledge International (nd), open data are raw digital data, related to government functions, which should be freely available to anyone to use, repurpose and re-publish as users wish and be absent mechanisms of control like restrictive licenses. According to Canada's Open Government Plan, which promotes open data as a proactive operating procedure, standards 
should improve the transparency and comparability of public information and government services (Government of Canada 2016). Governments at the subnational level see value in opening data, among them, to encourage local economic development, enhance service delivery, provide internal business intelligence, and increase public accountability (Sieber \& Johnson, 2015). Standards can make it easier for third party developers to create one product that serves multiple locales (Eaves, 2009; McHugh, 2013). Standardized data establish benchmarks in assessing whether governments achieve their goals in publishing open data (Davies \& Perini, 2016; Vetrò et al. 2016), for example in monitoring contracts and detecting corruption (Davies, Perini, \& Alonso, 2013). In addition, data standards enable positive economic feedback cycles by easing accessibility to and implementation of the data and sustain innovation over time (Russell, 2014). Not only opening government data enables the benefits, but so also does standardizing that open data.

Given the promises offered by standardizing open data, the open data community disagrees on precisely what constitutes a standard. Character encoding standards, such as UTF-8, and file formats, such as CSV, can be considered standards that are fundamental for sharing open data; others argue that only shared vocabularies can guarantee interoperability (Goëta \& Davies 2016). A lack of consistent definition has resulted in confusion and miscommunication among developers and users of open data. The XKCD cartoon (Figure 1) describes both the search for a universal standard that fits all cases and the likely consequence of that search. Choice of standards is more art than technical design, representing a battle for dominance and constituting a durable feature of information technology (Shapiro \& Varian, 1999).

HOW STANDARDS PROLIFERATE:

(SEE: A/C CHARGERS, CHARACTER ENCODINGS, INSTANT MESSAGING, ETC)

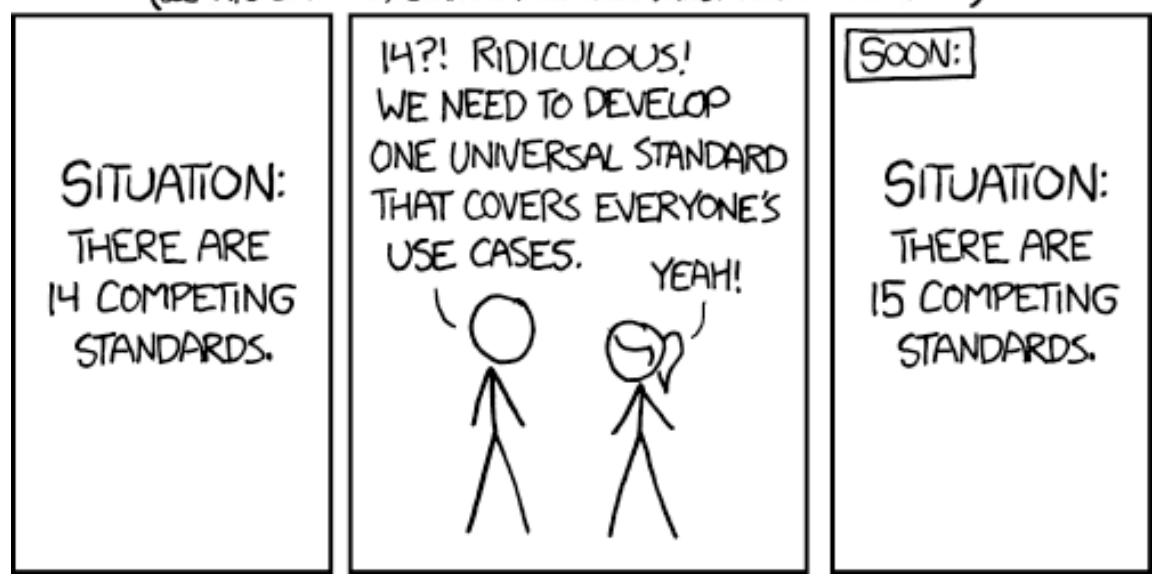

Figure 1. The problem with standards summarized in cartoon form. (Source: https://xkcd.com/927/)

The literature has yet to identify which standards for civic data, ${ }^{1}$ like GTFS, are "best" to open up government data. Indeed, prior to this research there existed no inventory of civic open data

\footnotetext{
${ }^{1}$ We use civic data, open data and open government data interchangeably in our paper.
} 
standards. Such insights could inform civic open data providers about which standards to choose prior to implement and deter providers from standards that lock in users. By civic open data providers, we refer to entities that provide data about government functions. This systematic search for metrics for open data is conducted within a larger project that works with approximately 125 North American cities (REDACTED). These experiences have informed the paper, in terms of what characteristics of open data are valued, what standardization is needed, and how information about standardization should be presented. In this paper, we first try to disentangle the confusion about what a standard is in the open government data community. We then identify predominant civic open data standards from high value domains (e.g., transportation, elections) and create a framework by which to evaluate these standards. Fundamentally, our paper addresses two questions: How do we tell a good standard from a bad standard? How do we even know what an open data standard is?

\section{Characterizing an open government data standard}

A data standard refers to "agreements on representations, formats, and definitions of common data" (Public Health Standards Consortium, n.d.). At a basic level, standards rely on a human process of agreement and collaboration to establish a norm. Individuals may disagree about the norms because, definitionally, a standard introduces clarity in areas where diversity is no longer desired (Aalders \& Hunter, 2009) and it can replace experimentation (e.g., with different data categories) with conformity (Robinson et al., 2009, p. 11). Palfrey and Gasser (2012, p. 21) assert that " $[\mathrm{t}]$ he human dimension of whether and how people can understand one another and work together often matters far more than whether technologies can pass data back and forth." Standards are not naturally emergent or obvious. There is no perfect standard and standards development is situational. GTFS was developed by Google in partnership with the City of Portland, Oregon. Goëta and Davies (2016, p. 17) suggest that "Had the initial collaboration taken place with another locality, it is possible to imagine that GTFS would have looked quite different."

A robust literature exists on open data but not on open data standards. Existing themes for open data include barriers to adoption (Janssen, Charalabidis, \& Zuiderwijk, 2012; Huijboom \& Van den Broek, 2011; Zuiderwijk \& Janssen, 2014), digital divides in access (Gurstein, 2011), and value and impacts (Sieber \& Johnson, 2015; Davies \& Perini, 2016). These articles acknowledge an absence of and need for standards. Huijboom and Van den Broek $(2011$, p. 8) surveyed numerous countries' open data strategies, where respondents identified a "lack of open data standards between (levels of) government organisations ... as a barrier to open data usage by citizens and businesses and subsequently new open data policy". The International Open Data Charter (2015, p. 5), an agreement made by global leaders about best practices and principles for open data policy, proposes to "engage with domestic and international standards bodies and other standard-setting initiatives to encourage increased interoperability between existing international standards, support the creation of common, global data standards where they do not already exist, 
and ensure that any new data standards we create are, to the greatest extent possible, interoperable with existing standards".

Literature that considers open data standards tends to exist in best practices guidelines, nongovernmental and governmental reports, or technical documentation. GTFS, considered the "gold" standard for open data (e.g., McHugh, 2013), is largely discussed as a matter of technical specifications among domain experts, like transit specialists. Or the treatment of standards is normative, in how can it achieve a specific goal. Open311 is an open standard for service requests. Open 311 is generally considered in a larger context of how standards can improve citizen feedback (Offenhuber, 2015) or further private entrepreneurship and government efficiency (Suri, 2013). Research also has been directed towards the construction of standards, for example for domains like 311 municipal service calls (Nalchigar \& Fox, 2014) or assess the quality of generic open data sets (Vetrò et al., 2016). They do not define or evaluate the performance of open data standards themselves. Reasons likely include the relative newness of open data which drive government focus on simple publishing of data. Standards may be seen as inevitable, naturally emergent, largely technical, or frankly dull (Lampland \& Star, 2008).

Goëta and Davies's (2016) analysed three standards of increasing complexity: the common data exchange format CSV (comma-separated values), GTFS and the international aid transparency initiative (IATI) standard. Standards "involve much more than a simple operation in which data producers would use the "save as' menu item and switch the format" (p. 24). Instead standards usage manifest organizational politics and valuation, which can serve practicality (CSV) or respond to demands from developers (GTFS) or necessitate the creation of intermediate tools and actors (IATI). We argue that understanding of open data standards is still so muddy that, for governments to use the standard, they need information as to their utility.

Goëta and Davies (2016) do not directly compare the three standards. Comparing a spreadsheet format to two domain-specific schema highlight a key difficulty in discussing open data standards: people consider as standards numerous overlapping concepts. Table 1 shows what we call the open data standards "stack". At one level there is metadata, which documents the "who, what, when, where, how, and why of a data resource" (https://www.fgdc.gov/metadata). While metadata may be a necessary condition for sharing data, Poore (2010), who was involved in the creation of the federal geographic data committee metadata framework, considers metadata a retreat from standards. Metadata only describes content; it does not force a structuration of content. One level up describes structuration that enables the exchange of data (file formats and character encoding), which can vary in their level of machine readability, openness of formats and descriptions (Geiger and von Lucke, 2012). At the next level is structuration of specific content within a dataset (e.g., geographic coordinates expressed as latitude and longitude). We then move from an ability to exchange data to its interoperability with other datasets (Davies, 2010). These standards utilize technical data elements such as data schemas and unique identifiers to relate independent datasets stored in databases or tagged content within lists. 
Table 1. The standards stack that describes different conceptualizations of standards

\begin{tabular}{|c|c|c|c|}
\hline Name & Description & Benefit/Goals & $\begin{array}{l}\text { Chief Application } \\
\text { for Open Data }\end{array}$ \\
\hline Metadata & $\begin{array}{l}\text { Documents/catalogues a } \\
\text { dataset, e.g., in terms of source, } \\
\text { ownership, and purpose. }\end{array}$ & $\begin{array}{l}\text { Increases discovery, especially } \\
\text { when government datasets are } \\
\text { not centralized. Improves } \\
\text { credibility of data because } \\
\text { information like provenance are } \\
\text { known. }\end{array}$ & $\begin{array}{l}\text { DDL, CKAN } \\
\text { Metadata } \\
\text { (according to Reich } \\
\text { \& Holfig, 2013), US } \\
\text { Federal Geographic } \\
\text { Data Committee } \\
\text { (FGDC) }\end{array}$ \\
\hline $\begin{array}{l}\text { Character } \\
\text { Formats }\end{array}$ & $\begin{array}{l}\text { Encodes data in machine- } \\
\text { readable form. }\end{array}$ & Enables data exchange. & UTF-8 \\
\hline File Formats & $\begin{array}{l}\text { Structures arrange-ment of data } \\
\text { in a dataset ("file"). Structure } \\
\text { informs software how to } \\
\text { render, process, and save data. }\end{array}$ & $\begin{array}{l}\text { Enables data exchange. Makes } \\
\text { data compatible with and } \\
\text { comparable across software } \\
\text { packages. In open data, has a } \\
\text { normative element: there are } \\
\text { preferred formats (e.g., csv and } \\
\text { not pdf). }\end{array}$ & $\begin{array}{l}\text { CSV, PDF, SHP, } \\
\text { HTML }\end{array}$ \\
\hline $\begin{array}{l}\text { Atomic } \\
\text { standards }\end{array}$ & $\begin{array}{l}\text { Within a schema, defines how } \\
\text { basic elements of data must be } \\
\text { represented. May represent } \\
\text { individual data values or a } \\
\text { combination of data values. For } \\
\text { example, a date and time could } \\
\text { be formatted as "2017-01- } \\
\text { 01T13:00:00Z" (the ISO8601 } \\
\text { representation for "January 1, } \\
2017 \text { at 1pm Universal } \\
\text { Coordinated Time"). Spatial } \\
\text { location could be represented } \\
\text { as “+37.5665,+126.9780" } \\
\text { (WGS84 latitude and longitude } \\
\text { coordinates for Seoul, South } \\
\text { Korea). }\end{array}$ & $\begin{array}{l}\text { Allows for domain-independent } \\
\text { discovery and linkability (e.g., on } \\
\text { location). }\end{array}$ & $\begin{array}{l}\text { Centroids for } \\
\text { census tracts }\end{array}$ \\
\hline Schema & $\begin{array}{l}\text { Organizes and demonstrates } \\
\text { relations between data in a file. } \\
\text { Structure described in a } \\
\text { developer-designed formal } \\
\text { language. Often derived from } \\
\text { eXtensible Markup Language } \\
\text { (XML). }\end{array}$ & $\begin{array}{l}\text { Enables data interoperability. } \\
\text { Dependent on choice of words in } \\
\text { schema, may enable human } \\
\text { readability (e.g., in Open } 311 \\
\text { status ("submitted", } \\
\text { "assigned",...). }\end{array}$ & GTFS, Open311 \\
\hline $\begin{array}{l}\text { Unique } \\
\text { Identifiers }\end{array}$ & $\begin{array}{l}\text { Within a dataset, provides } \\
\text { exclusive references for } \\
\text { organisations, locations and }\end{array}$ & $\begin{array}{l}\text { Allows for discoverability, } \\
\text { traceability, and linkability of } \\
\text { things across multiple data }\end{array}$ & $\begin{array}{l}\text { Open Contracting } \\
\text { ID (OCID) }\end{array}$ \\
\hline
\end{tabular}




\begin{tabular}{|c|c|c|c|}
\hline & $\begin{array}{l}\text { things, which e.g., allows one to } \\
\text { definitively distinguish one } \\
\text { organization from another. }\end{array}$ & sources, databases. & \\
\hline $\begin{array}{l}\text { Controlled } \\
\text { vocabulary, } \\
\text { taxonomies, } \\
\text { thesauri, } \\
\text { ontologies }\end{array}$ & $\begin{array}{l}\text { For a specified domain (e.g., } \\
\text { transport), list of predefined, } \\
\text { authorised terms and } \\
\text { structures. Lists are frequently } \\
\text { hierarchical, formal (a proper } \\
\text { unvarying set), contain } \\
\text { completely defined entities } \\
\text { (e.g., this item is in this category } \\
\text { if and only if the following } \\
\text { conditions are met), and often } \\
\text { contain types, properties, and } \\
\text { interrelationships of the } \\
\text { entities. }\end{array}$ & $\begin{array}{l}\text { Provide semantic to a system. } \\
\text { Controlled vocabularies are } \\
\text { particularly important for } \\
\text { domain-specific standards. }\end{array}$ & $\begin{array}{l}311 \text { Ontology } \\
\text { (Nalchigar } \\
\text { \& Fox, 2014), } \\
\text { http://vocab.linked } \\
\text { data.es/datosabier } \\
\text { tos/ }\end{array}$ \\
\hline $\begin{array}{l}\text { Linked Open } \\
\text { Data }\end{array}$ & $\begin{array}{l}\text { Combines a Uniform Resource } \\
\text { Identifier (URI, commonly } \\
\text { known as a website address), } \\
\text { which also functions as a unique } \\
\text { identifier, deployed in an } \\
\text { ontology (e.g., RDF) and used } \\
\text { with open data sources. Often } \\
\text { used for unrelated data. }\end{array}$ & $\begin{array}{l}\text { Creates permanent storage of } \\
\text { and relationships among datasets } \\
\text { and data. It enables } \\
\text { discoverability and indexability. } \\
\text { Provides semantics to unrelated } \\
\text { data. }\end{array}$ & $\begin{array}{l}\text { La Fundación } \\
\text { Centro Tecnológico } \\
\text { de la Información y } \\
\text { la Comunicación } \\
\text { http://opendataco } \\
\text { n.org/beyond-raw- } \\
\text { data-creating-city- } \\
\text { standards-for- } \\
\text { priority-datasets/ } \\
\text { US Patent Office }\end{array}$ \\
\hline $\begin{array}{l}\text { Quality } \\
\text { metrics, } \\
\text { ratings, } \\
\text { filters, and } \\
\text { indicators }\end{array}$ & $\begin{array}{l}\text { Evaluate quality (e.g., accuracy } \\
\text { or completeness) of an } \\
\text { individual dataset or open data } \\
\text { provisioning. }\end{array}$ & $\begin{array}{l}\text { Allows for valuation of open data, } \\
\text { benchmarking of organization to } \\
\text { organization against a set of } \\
\text { metrics. }\end{array}$ & $\begin{array}{l}\text { Open Cities Index, } \\
\text { Open Data } \\
\text { Barometer, Global } \\
\text { Open Data Index, } \\
\text { Open Data } \\
\text { Inventory }\end{array}$ \\
\hline $\begin{array}{l}\text { Compliance } \\
\text { and } \\
\text { Certification }\end{array}$ & $\begin{array}{l}\text { Confirms certain characteristics } \\
\text { of data element or data } \\
\text { producer, which are verified } \\
\text { against formal criteria. }\end{array}$ & $\begin{array}{l}\text { Assesses compliance. May be } \\
\text { conditional to access (e.g., } \\
\text { markets, services). May be } \\
\text { involuntary agreement that } \\
\text { ensures minimum level of quality } \\
\text { (de jure). }\end{array}$ & $\begin{array}{l}\text { World Council on } \\
\text { City Data's } \\
\text { implementation of } \\
\text { ISO } 37120 ; \\
\text { Extractive } \\
\text { Industries } \\
\text { Transparency } \\
\text { Initiative } \\
\text { (https://eiti.org) }\end{array}$ \\
\hline
\end{tabular}


At higher levels standards combine data interoperability with semantics. Semantics ensure that data providers are reporting the same activity by using common codes to encapsulate and express the data. Standards may define a domain-specific vocabulary, for example to enumerate amounts of public expenditures or types of crime (http://govex.jhu.edu/enabling-civic-datastandards). Ontologies build on vocabulary by fully describing and hierarchically relating elements to each other. Nalchigar and Fox (2014) proposed an ontology for the Open311 schema in which, for example, a service_request has a specific Address and 311 \{complaint\} Type; it has to be handled by some Agency. The most discussed standard in the international community is linked open data for government data (i.e., ontologies plus permanent web links) (Shadbolt et al., 2012; Geiger \& von Lucke, 2012). According to Shadbolt et al. (2012), linked open government data reduces state monopoly over many useful datasets. The argument is that data only achieves its greatest data and semantic interoperability when it is made available on the world wide web in a human readable format.

For completeness sake, we include a final level of standards that assess quality, compliance, and certification, which we collectively label performance. These standards indicate how well a dataset functions, for example in terms of its completeness or how well a government is performing in its overall open data provisioning. Some of these are indicators (how city x performs on certain key metrics); others are compliance standards (e.g,. city must meet this minimum number of datasets to be considered a part of the association). Standards that assess the quality of open government data (e.g., Vetrò et al., 2016) are conceptually distinct from standards that provide for interoperability of open data. However, the concepts of quality and interoperability, as well as metadata and possibly even certification are entangled in the empirical operations of standards.

Frequently levels exhibit no hard boundaries. Open 311 and GTFS exemplify how standards

often build on each other (Goëta \& Davies, 2016, p. 15). According to CKAN, the comprehensive knowledge archive network that supports an open source publishing tool for open data, "DCAT (Data Catalog Vocabulary) is a standard vocabulary for describing datasets in data catalogues." (https://ckan.org/open-standards/), yet DCAT is also considered metadata (Reich \& Holfig, 2013). While it is hard to disentangle standards in practical terms, Table 1 aims to conceptually organize standards in the stack.

\section{Methodology}

We utilized a qualitative systematic review (QSR) to identify metrics that could evaluate standards for open data. Like other systematic reviews, QSR is exhaustive and synthetic; QSR "looks for 'themes' or 'constructs' that lie in or across individual qualitative studies" (Ortega, Lopez-Briz \& Fraga-Fuentes, 2016, p. 25). The results are not additive (as in quantitative systematic reviews) but interpretive to determine "where the 'weight' of the evidence lies" (Butler, Hall \& Copnell, 2016, p. 194). QSR is popular in health and community studies; it seeks to standardize "participant experiences and perceptions, rather than assess the effectiveness of an intervention" (Butler, Hall 
\& Copnell, 2016, p. 241). QSR can foreground the role of people in crafting technical standards (Palfrey \& Gasser, 2012; Russell, 2014).

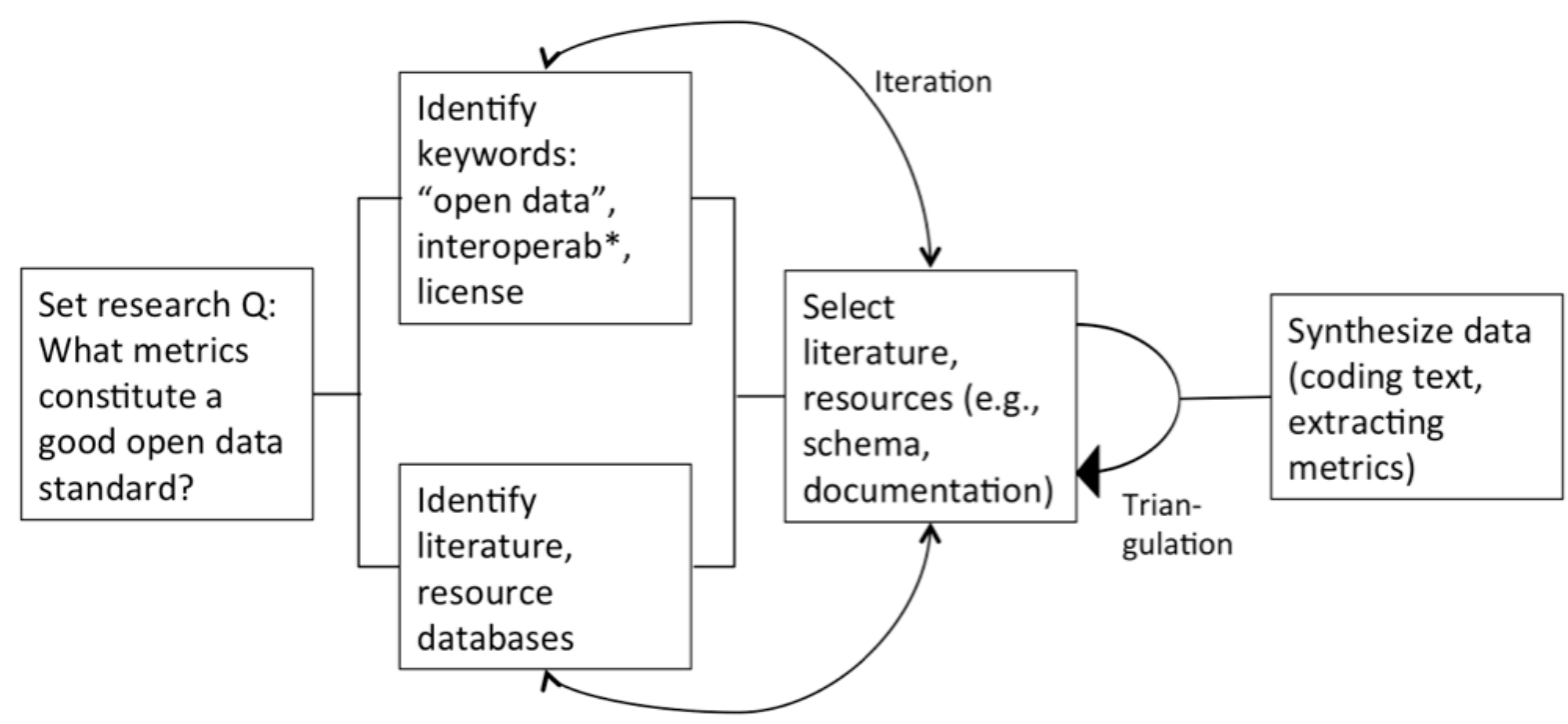

Figure 2. Qualitative Systematic Review for Open Data Standards Metrics

Figure 2 describes our methodology. After establishing the research question, we identified keywords and other search criteria (e.g., could apply to data derived from government). Above we showed that standards publishers may refer to their standards in various ways: as application programming interfaces (APIs), file formats, schemas, vocabularies, and specifications. A "mislabel" should not preclude an article or standard from selection. We also refined search criteria. For example, metadata standards that were not rooted in specific government domains or specifically related to government practices, such as RDF and Dublin Core Metadata Element Set, were excluded from examination.

We then identified the literature, which included academic (e.g., best practices in standards processes, interoperability theory) as well as grey literature (e.g., Govtech.org, Medium.com, municipal blog posts). Discussion of standards frequently linked back to principles (metrics) of open data so we included sites like https://www.w3.org/TR/gov-data/, https://www.w3.org/DesignIssues/LinkedData.html, https://opendatacharter.net/principles/, and https://sunlightfoundation.com/policy/documents/ten-open-data-principles/.

We narrowed our resource base to exhaustively examine standards for specific open datasets. We chose twelve datasets (Table 2), which are considered to be of high value for governments to publish openly (https://opendatacharter.net/resource/g8-open-data-charter/). Ours came from a curated list for the Open Knowledge Foundation (https://index.okfn.org/dataset/) and also from an inventory of the most commonly opened municipal datasets in Canada (Currie, 2013). From the datasets, we found 22 standards that provided sufficient documentation to indicate a strategy for data standardization and the standard itself. For each standard, we read discussion forums, google groups, email threads, popular press accounts, and blog posts. We also read the technical 
documentation, github repositories, schema, and instances of the schema in use (Antrium \& Barbeau, 2013). For example, we drew on the success of highly described/visible standards, like GTFS, in which developers made a conscience decision to publish in the "easy to use" format CSV (McHugh, 2013).

Table 2. List of open data standards by high value dataset

\begin{tabular}{|c|c|}
\hline Dataset & Standards \\
\hline Building Permits (1) & Building Land and Development Specification (BLDS) \\
\hline Elections Results (5) & $\begin{array}{l}\text { Results data spec V2, Election Data Format, Election Markup Language, NIST's Common } \\
\text { Election Format Project, Voting Information Project }\end{array}$ \\
\hline Transit Real-Time (2) & GTFS, Service Interface for Real-Time Information (SIRI) \\
\hline Road construction (1) & Open511 API \\
\hline Crime statistics (1) & SPOTCrime Open Crime Standard \\
\hline Zoning (3) & $\begin{array}{l}\text { MassGIS Datalayer De-Facto Standard, Region Land Information System (RLIS) Discovery, } \\
\text { Land Based Classification (LBCS) Standard - OWL2 }\end{array}$ \\
\hline Public Facilities (1) & Open311 Inquiry API \\
\hline Food Safety (1) & Local Inspector Value-Entry Specification (LIVES) \\
\hline $\begin{array}{l}\text { Procurement Contracts } \\
\text { (1) }\end{array}$ & Open Contracting Data Standard \\
\hline Annual Budgets (4) & $\begin{array}{l}\text { Fiscal Data Package, Operating Budget Schema, Capital Budget Schema, Vocabulario para } \\
\text { la representación de datos sobre presupuestos de entidades locales }\end{array}$ \\
\hline $\begin{array}{l}\text { Geospatial boundary } \\
\text { files, points (1) }\end{array}$ & OpenAddress Specification \\
\hline Service Requests (1) & Open311 API \\
\hline
\end{tabular}

We searched for patterns, that is what standards had in common. Because these were domain standards (e.g., transportation, elections), we focused on standards that use specified data values and vocabularies, data schemas, and unique identifiers to make the data more usable for cities. Therefore, we excluded from the research results standards for measuring the quality and availability of open datasets. We developed metrics based on these patterns. To effect triangulation, the authors conferred to ensure the same patterns were being identified. Finally, we examined 22 standards to explore compliance with the metrics since not all standards would demonstrate each metric. 


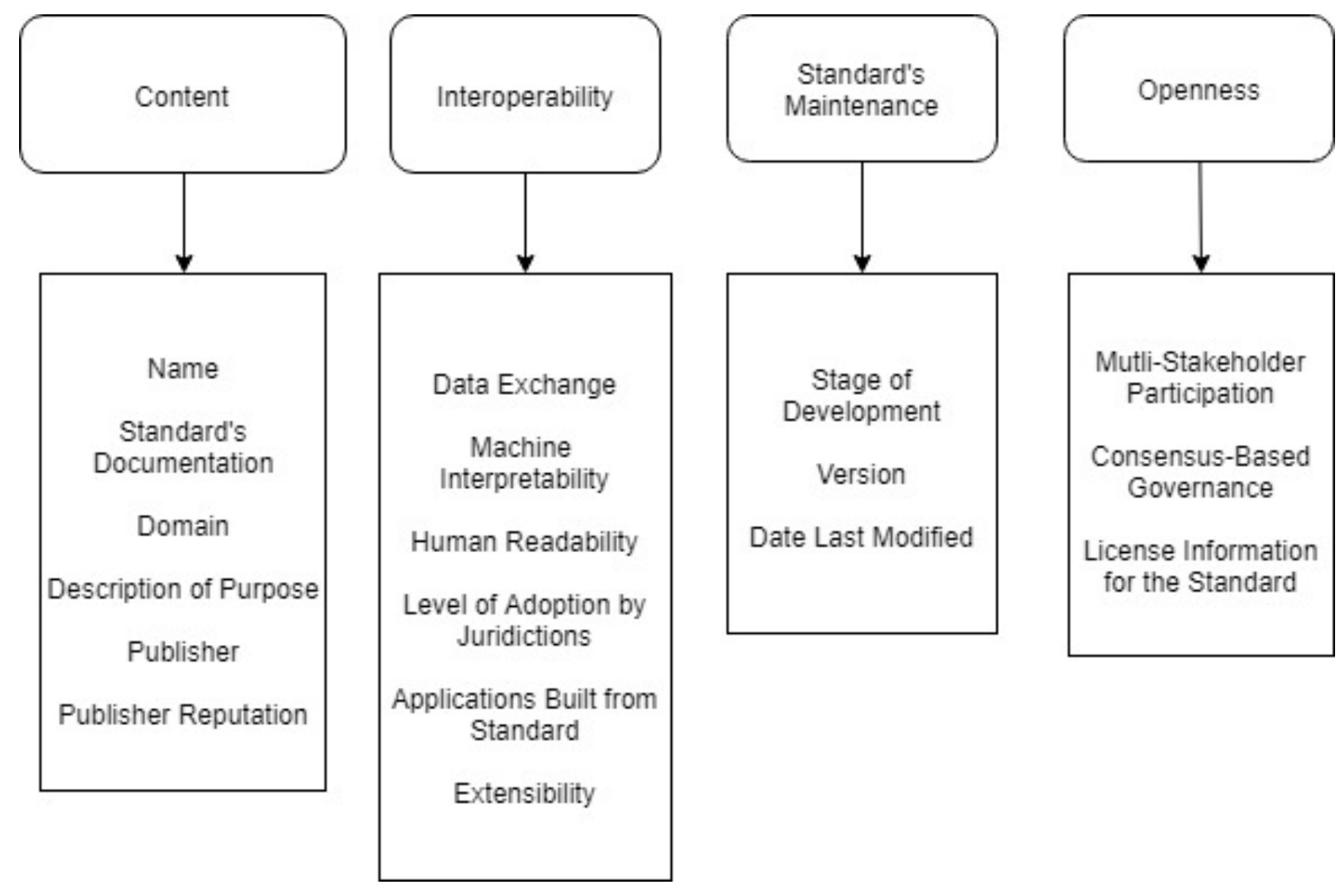

Figure 3. Quality metrics for civic open data standards

\section{Metrics of civic open data standards}

We derived 18 metrics, spanning who is the publisher of the standard to the its level of human readability. We organized the metrics into categories (Figure 3). Categorization was informed by Palfrey and Gasser's (2012) concept of interoperability theory, which includes the technical layer, the data layer, the human layer and the institutional layer. Our interoperability level contains technical details like file formats and extensions. Our level of openness maps onto the institutional layer as it concerns the process of standards development and use as well as legal frameworks. Some of these metrics are inspired by McKinney and Ashlock (nd), for example, ease of implementation and governance model.

The metrics were assigned qualitative values denoting compliance: nominal (present/not present; name) or ordinal (high-medium-low) measures. Our goal was to assess the quality of civic open data standards themselves as opposed to the quality of the underlying datasets. Standards that assess the quality of individual datasets (Vetrò et al., 2016) are conceptually distinct from standards that provide for interoperability of open data, although quality and interoperability are intertwined in the actual operations of standards. Our metrics provide background about the who, what, where, and how of the open data standards process across domains. They cover the content (e.g., who creates the standard's documentation), interoperability (e.g., how machine or human 
readable the standard is), legality (e.g., which license is applied to the standard), and the standard's process (e.g., how was the standard developed and how is it maintained). Details on each category for our "performance standard of standards" is below.

\subsection{Content Standards Characteristics}

Content characteristics provide the descriptive background information about the standard: name of domain, standard's publisher, description and purpose, standard's publisher reputation, and a standard's own documentation (Table 3). This set of metrics resemble the simplified Dublin Core standard for specifying metadata of online resources.

In addition to describing the standard, these metrics act as measures of a standard's quality, especially in cases when characteristics of the standards are absent, incomplete, or ill-defined. The importance of metrics to assess descriptive content are well-articulated in literature on metadata standards and considerable research has been conducted on evaluating the quality of metadata for government datasets (Reiche \& Hofig, 2013; Ochoa \& Duval, 2006). This research has been informed by useful characteristics for improved quality of metadata like provenance, timeliness, completeness, richness, accessibility and accuracy of data as well as conformance to expectations (ibid.). These characteristics to assess metadata tend to use numerical measures, but we eschew the quantitative in favor of a more qualitative approach consistent with the QSR.

We examined the content characteristics of the 22 standards in Table 2 . We found that a name alone cannot fully explain the standard. The way standards are named do not necessarily match our definitions in Table 1 nor common understandings of terms like APIs. Documentation of these standards is generally hosted on a city's website or on a codesharing site like GitHub. Websites offer "how-to" information to ease the implementation of standards and also can describe open data standards initiatives and implementations (e.g., Open511). GitHub is an open repository because it allows anyone to report issues and change content, although GitHub suffers from a lack of human readability.

Publishers and co-publishers of standards for open data include international standard bodies (4 standards), private technology companies (6 standards), city and regionals governmental agencies ( 5 standards) and civil society organizations ( 9 standards). Municipal agencies that act as custodians of open datasets may prefer to implement a standard based on the reputation of its publisher. For instance, publishers of open data may prefer to partner and entrust their data with experts from a well renowned technology firm or an accredited standards organization.

Conversely, custodians of open data may wish to partner with another organization that intimately understands the inner workings, requirements, and values of public sector organizations. In general, preferences, if any, about types of publishers are not yet well understood.

Finally, domain is an important metric because it identifies the potential purpose for using the data for civic governance. By identifying the domain, one can not only determine from where in government the data was originally generated and why, but also deduce potential applications for the repurposed data. Domain is thus linked to the description and purpose metric, which account for the standard's components and potential applications. 
Table 3. Content metrics for open data standards

\begin{tabular}{|c|c|c|c|}
\hline $\begin{array}{l}\text { Descriptive } \\
\text { content } \\
\text { characteristics }\end{array}$ & Description & $\begin{array}{l}\text { Value } \\
\text { Type }\end{array}$ & Sources \\
\hline Name & Identifies the standard being evaluated. & Name & $\begin{array}{l}\text { Reiche \& Hofig, } \\
\text { 2013; Ochoa \& } \\
\text { Duval, } 2006\end{array}$ \\
\hline $\begin{array}{l}\text { Standard's } \\
\text { Documentation }\end{array}$ & $\begin{array}{l}\text { Describes technical information about the formatting of the } \\
\text { standard, information about implementation, and any timeline } \\
\text { for future developments to the standard. }\end{array}$ & Hyperlink & $\begin{array}{l}\text { Federal } \\
\text { Geographic Data } \\
\text { Committee } \\
\text { (FGDC) }\end{array}$ \\
\hline Domain & $\begin{array}{l}\text { Helps identify potential uses for the standardized data. } \\
\text { Accounts for specific data vocabularies that are rooted within a } \\
\text { domain. }\end{array}$ & Name & $\begin{array}{l}\text { G8 Open Data } \\
\text { Charter }\end{array}$ \\
\hline $\begin{array}{l}\text { Description of } \\
\text { Purpose }\end{array}$ & $\begin{array}{l}\text { Describes why publishers conceived the standard and provides } \\
\text { a justification for its proposed implementation. }\end{array}$ & Text & FGDC \\
\hline Publisher & $\begin{array}{l}\text { Details the coordinating body or bodies and implies the degree } \\
\text { of partnerships and collaboration involved in the standard's } \\
\text { development. Provide a basis for judging utility because it } \\
\text { communicates who prepared the metadata and whether they } \\
\text { have expertise in the relevant domain. }\end{array}$ & Name & $\begin{array}{l}\text { FGDC; Bruce and } \\
\text { Hillmann, } 2004\end{array}$ \\
\hline $\begin{array}{l}\text { Publisher } \\
\text { Reputation }\end{array}$ & $\begin{array}{l}\text { Provides background information about an organization or } \\
\text { company and their level of expertise regarding standards. }\end{array}$ & Text & $\begin{array}{l}\text { Reiche \& Hofig, } \\
2013\end{array}$ \\
\hline
\end{tabular}

\subsection{Interoperability Metrics}

Interoperability is a fundamental driver for open data. Interoperability of datasets promises to optimize limited government resources because of its promised efficiencies in data handling and its potential for economic development. Demonstrations of interoperability may make open data publishing less vulnerable to budget cuts relative to mission-critical government services. Our metrics for interoperability assess how well each standard is structured, not only from a technical standpoint, but also in a way that is humanly accessible to city personnel and data re-users. Human readability is especially important for the public sector that cannot afford technical expertise and must contend with staff turnover. Our experience has been the loss of staff can effectively reset open data initiatives.

Table 4 characterizes varying levels of interoperability. As suggested in Table 1, a minimal standard to render a dataset interoperable is the choice of file format. Numerous file formats exist for data publishing, including XML, RSS feed, CSV, RDF, JSON, TXT, XLS(X), KML, PDF, HTML, DOC(X), as well as scanned documents (Suszan, 2014). We found that, of the 22 standards we surveyed, 12 had data provided in CSV or XLSX; seven allowed for the data be 
provided in the more technically advanced JSON file format. Berners-Lee (2010) ranked file formats in his five star scheme to gauge interoperability of open data. According to this rating system, publishing the data in a XLSX format receives a lower grade than publishing the data in CSV. Proprietary formats like XLSX requires the user to purchase a license to open the data; whereas nonproprietary uses an open license and permits the user to open the data free of charge. PDF is a considered an "infamous" open data file format. While a pdf is open because end users have freedom of access, it is technically not machine readable (Geiger \& von Lucke, 2012) because the data cannot "be filtered, sorted, reshaped and manipulated without copying/pasting or re-typing in data" (Davies, Perini, \& Alonso, 2013, pp. 6-7). From a political standpoint, PDFs or scanned images of text can facilitate an "open washing" approach in which governments publish the data in non-extractable formats and then claim compliance with openness (Sieber \& Johnson, 2015).

The UK Cabinet Office (2015) states that benefits of open data cannot be achieved unless data contains some degree of semantic organization that can be interpreted by machines (e.g., via specialty software or apps). Most open data standards discussions focuses on increasing machine to machine interpretability. Researchers argue that standards should move up the standards stack through identifiers, controlled vocabulary, schema, or ontologies (Fox, 2013). For instance, linked open data requires establishing standard vocabularies, HTML resources enriched with metadata, semantics, and identifiers, with permanent Uniform Resource Identifiers (URIs) (Bennett and Harvey, 2009). Structuring the data to maximise automation and linkability does not necessarily provide open data that is practical for different types of users. Goëta and Davies (2016) point out that XML is well suited for exchange of structured data between machines but is far less usable for web developers or users who are familiar with tabular data with CSVs. An organization may desire a particular standard because it provides high levels of machine readability but no one will use it.

Of the 22 standards that we used in our QSR, all were expressed as schema. Only two exhibited a higher level of machine interpretability. ODI employs .rdf in their election data format. The Vocabulario para la representación de datos sobre presupuestos de entidades locales specifies a controlled vocabulary for local budget data.

The discourse on interoperability can emphasize ease for machines at the expense of human understanding. Human readability is the degree to which a data standard encodes the data by using easily identifiable text. Human readability resembles Ochoa and Duval's (2006) metadata quality metric of "accessibility", meaning the extent to which metadata is cognitively, physically, and logically accessible to people. Human readable standards support openness by allowing producers or consumers of open data to read the standardized datasets in raw form without mediating software. Indeed, human readability suggests a social contract with data users (Russell 2014). If the government is to achieve transparency and accountability in its open data then an educated public should be able to parse what is stored in the dataset (Sieber \& Johnson, 2015).

Human readability is difficult to ascertain. We first provide a subjective rating of its readability based on our QSR, which includes reading the raw data for comprehensibility. Our 22 standards rate from low to medium. Because most standards are optimized for machine 
interpretability, the raw data usually has to be mediated (e.g., visualized) by another application before it is read by humans. This requires intervention by developers, who not only write the software but sustain it through any changes (e.g., in the standard or supporting software like browsers). More importantly, it requires the users trust the developers "got the data right" in its interpretation, a potential problem considering that certain datasets (e.g., subcontracting, financial transactions) are published precisely because of a lack of trust in government. An example of a high level of human readability is EML, the election markup language, which was developed by election experts and is considered to be easy to read (Kitcat, 2004). Conversely, Vocabulario para la representación de datos sobre presupuestos de entidades locales has low human readability because it requires computational ontology software (e.g., Protege-OWL) to read the raw data.

The last three metrics for interoperability relate to a standard's usability in terms of government adoption, extensibility, and applications utilizing the standard. Level of adoption by cities is represented by names (a nominal value) and number (an integer value) of cities that have adopted the standard. A high integer value indicates whether a standard is well known and the extent it is implemented by cities. Cities may be inclined to adopt a standard that is widely implemented for two reasons. Interoperability of the datasets increases as more cities implement the standard (e.g., with adjacent jurisdictions adopting GTFS) and level of adoption can communicate to potential adopters that the standard is successful. The latter reason is supported by Rogers's (2003) findings on the the diffusion of innovations, which finds a positive correlation between an innovation's vicarious trialability (to what extent someone can observe others' experience with the technology before adopting it) and its observability (to what extent someone can actually observe the advantages of the technology) with an increased rate of adoption.

Publishers of the 22 standards occasionally provide information about the jurisdictions that use the standard. We observed that, with few exceptions, accredited standards bodies did not track jurisdictions that had adopted the standard. (The exception was open contracting.) We speculate that adoption is not tracked because the standards bodies focus on mediating interests during the standard's creation process. Of the 22 standards, the frequency of jurisdictional usage is highly skewed. As of September 2016, 1000 transit agencies were using GTFS (https://code.google.com/archive/p/googletransitdatafeed/wikis/PublicFeeds.wiki). BLDS has 14. For six standards we could identify no users.

Even when interoperability is maximized through many cities using the standard, there are limits to conflating a standard's level of adoption with suitability of the standard to specific needs of the city and data re-users. Applications built from the standard indicate whether end users, here third party app developers, engage with the standard, that is whether the data is popular, repurposable, and valued among data re-users. Our review of the 22 standards shows a great unevenness about applications. Eighty-seven applications have been built from GTFS schematized data (https://www.transitwiki.org/TransitWiki/index.php/Category:GTFSconsuming applications). We found no applications for nearly half (10) of the standards. A lack of applications once again suggests that "perfect" standards may be developed; that does not mean people will build on them. 
Table 4. Interoperability metrics for open data standards

\begin{tabular}{|c|c|c|c|}
\hline $\begin{array}{l}\text { Interoperability } \\
\text { Characteristics }\end{array}$ & Description & $\begin{array}{l}\text { Value } \\
\text { Type }\end{array}$ & Sources \\
\hline Data Exchange & $\begin{array}{l}\text { Formalizes data in a way that can be encoded into } \\
\text { character standards or data models. }\end{array}$ & $\begin{array}{l}\text { Name of } \\
\text { file } \\
\text { format }\end{array}$ & $\begin{array}{l}\text { W3C; OKF's } \\
\text { definition of an } \\
\text { open data } \\
\text { standard, } \\
\text { Suszan, 2014; } \\
\text { Davies, 2013; } \\
\text { McKinney \& } \\
\text { Ashlock, nd;.5 } \\
\text { Star }\end{array}$ \\
\hline $\begin{array}{l}\text { Machine } \\
\text { interpretability }\end{array}$ & $\begin{array}{l}\text { Organizes data into a syntax that a machine can } \\
\text { process without knowing the underlying content. } \\
\text { In this way, the data is portable and processable by } \\
\text { multiple applications. }\end{array}$ & $\begin{array}{l}\text { Numerica } \\
\text { I level in } \\
\text { standard } \\
\text { s stack }\end{array}$ & Table 1 \\
\hline Human Readability & $\begin{array}{l}\text { Encodes the data in a way that is understandable } \\
\text { (e.g., to lay experts), relevant to domain experts } \\
\text { and, to the extent possible, is expressed in plain } \\
\text { language. }\end{array}$ & $\begin{array}{l}\text { High, } \\
\text { medium, } \\
\text { low; } \\
\text { Rationale }\end{array}$ & $\begin{array}{l}\text { W3C; Palfrey \& } \\
\text { Gasser, 2012; } \\
\text { Ochoa \& Duval, } \\
2006\end{array}$ \\
\hline $\begin{array}{l}\text { Level of Adoption by } \\
\text { Jurisdictions }\end{array}$ & $\begin{array}{l}\text { Expresses the number of jurisdictions using a } \\
\text { standard }\end{array}$ & $\begin{array}{l}\text { City } \\
\text { names; } \\
\text { Count }\end{array}$ & $\begin{array}{l}\text { Aalders \& } \\
\text { Hunter, } 2009\end{array}$ \\
\hline $\begin{array}{l}\text { Applications Built } \\
\text { from Standard }\end{array}$ & $\begin{array}{l}\text { Identifies which third parties have developed } \\
\text { applications using the standard. }\end{array}$ & $\begin{array}{l}\text { Names } \\
\text { and } \\
\text { numbers } \\
\text { of third } \\
\text { party } \\
\text { applicati } \\
\text { ons }\end{array}$ & McHugh, 2013 \\
\hline Extensibility & Allows user to add to a standard's capabilities. & $\begin{array}{l}\text { "Yes", } \\
\text { "No"; } \\
\text { Descripti } \\
\text { on }\end{array}$ & $\begin{array}{l}\text { http://searchmi } \\
\text { croservices.tec } \\
\text { htarget.com/de } \\
\text { finition/extensi } \\
\text { ble; Shueh, } \\
2015\end{array}$ \\
\hline
\end{tabular}

Extensibility of standards refers to whether the standard has been altered to capture more information than originally designed. Extensibility allows a standard to "evolve" with emergent or location-specific needs. Extensibility also can correct for the inevitable information loss resulting from the need to conform across diverse sets of information (Zhu \& Wu, 2011, p. 2). Of the 22 standards surveyed, 11 included extensions. For example, a "Media handling" extension to 
Open311 allows for the uploading of image files from smartphones. GTFS was extended to address paratransit (Klopp et al., 2014). The Fiscal standard has 3 extensions. Extensibility is important for usability but can be antithetical to machine interpretability. This point of tension was acknowledged among creators of BLDS standard for open building permit data: "the [standards] group's struggle was to identify a compromise between requirements for granular level data (which data consumers pined for) and universal data that was more basic - yet that also was accommodating to diverse jurisdictions" (Shueh, 2015).

\subsection{MAINTENANCE OF STANDARDS CHARACTERISTICS}

Information about a standard's technical evolution and its maintenance over time assures users that the standard remains relevant to needs and technology trends over time. Table 5 shows the results of the QSR related to a standard's maintenance. Stage of Development is important since a draft standard will less likely be adopted compared to a standard ready to be put into production. A draft standard likely still requires tests for design conflicts or is awaiting feedback from the user community. All 22 standards specify whether they are in a draft (5) or in production stage (17). A production stage still allows for future modification, which we tracked through version numbers. A version number implies some maturation of development and duty of care to a standard. Fourteen of the 22 standards specify their version number. Two--the Election Markup Language and the Voting Information Project Specification--had a version number higher than 3. A high version number could indicate progress in the shared understanding of the domain (Raemaekers, Van Deursen, \& Visser, 2014). In the case of GTFS, it could imply the existence of standards "champions" leading change proposals (Antrium, 2017). The downside to this dynamism is the potential need to retrofit data to a new version (Goëta \& Davies, 2016). For instance, GTFS states as a guiding principle that changes to the specification be backward-compatible (https://developers.google.com/transit/gtfs-realtime/guides/guiding-principles). Versions may enable forward compatibility; they increase concerns about whether the new version will continue to work with older information technology.

Each standard contained a timestamp of when their documentation was last modified. A date is useful but can offer conflicting messages. A date far in the past may indicate the standard has stabilized or is no longer actively maintained. Seventeen of the standards were last modified by publishers between 2015-2017 and four were last modified from 2011 to 2014. One outlier, the Land Based Classification System, documented its most recent update to 2001. This standard is not highly machine readable, meaning it may not consider changes in technology as much as a standards that specify data formats and schemas. Overall, the majority of these standards have been updated recently, indicating that these standards have not become dormant and irrelevant to recent needs of users. 
Table 5. Maintenance metrics for open data standards

\begin{tabular}{|c|c|c|c|}
\hline $\begin{array}{l}\text { Standards } \\
\text { Maintenance } \\
\text { Characteristics }\end{array}$ & Description & Value Type & Sources \\
\hline $\begin{array}{l}\text { Stage of } \\
\text { Development }\end{array}$ & $\begin{array}{l}\text { Describes level of production; } \\
\text { sometimes works-in-progress are } \\
\text { made public online. }\end{array}$ & $\begin{array}{l}\text { "Draft"/“In } \\
\text { Production" }\end{array}$ & $\begin{array}{l}\text { Appeared in documentation of all } 22 \\
\text { standards }\end{array}$ \\
\hline Version & $\begin{array}{l}\text { Numbers changes in the standard. } \\
\text { Numbering can apply to both draft } \\
\text { and production standards. }\end{array}$ & $\begin{array}{l}\text { Version } \\
\text { number; Date }\end{array}$ & $\begin{array}{l}\text { Nelson, 2003; Klein \& Fensel, 2001; } \\
\text { Raemaekers, Van Deursen, \& Visser, } \\
\text { 2014; Goëta \& Davies, } 2016\end{array}$ \\
\hline Date Last Modified & $\begin{array}{l}\text { Shows the last time the standard's } \\
\text { documentation has changed. }\end{array}$ & Date & $\begin{array}{l}\text { Appeared in documentation of all } 22 \\
\text { standards }\end{array}$ \\
\hline
\end{tabular}

\subsection{Openness Characteristics}

Whereas open data is by its eponymous definition, open; the development of open data standards itself may not be. Russell (2014, p. 21) concludes that opening the standards development process reflects the principles of a participatory democracy, with fairness, transparency and due process, and a vibrant market economy, with negligible barriers to entry. He identifies two features of open standards processes: "well-defined procedures that guarantee public participation in the production of standards and liberal terms of access that allow public use of standardized technologies" (ibid.). We interpret that as public participation that includes multiple stakeholders, a process to resolve issues that is consensus-based, and a standards license that ensures liberal access (Table 6). Compared to the private sector where exclusive and restrictive control over standards development may represent a competitive advantage, government places a high value on a transparent process. In the US, open meetings/sunshine laws require that certain government agency processes provide access to meetings (easily accessible locations), electronic meetings, ample notification of the event, availability for public comment (Piotrowski \& Borry, 2010). Thus, for open data, principles of process openness and information accessibility extend to the data derived by government agencies.

We define multi-stakeholder participation as the engagement of a diverse set of individuals and groups implicated in the deployment of the standard. A diversity of stakeholders creates a rich dialogue of different perspectives and ensures consumers and producers of an innovation do not get left behind as the standards and technology evolve (Krechmer, 2006; Zhang, Dawes, \& Sarkis, 2005). Palfrey and Gasser (2014, p. 9) find multi-stakeholder approaches increase interoperability. For example, the UN Meeting on Data Interoperability notes that having diverse stakeholders 
decreases uncertainty and ambiguity of terms by enabling a common vocabulary across the broad range of users (Gonzalez Morales \& Orrell, 2017).

Based on the QSR, we found that standards development included groups from the lifecycle of the standard: data publishers, implementers of the standard (i.e., cities), and end users (those who deploy the standardized data such as citizens, researchers, and software companies). Groups originated from all sectors, including civil society, government, and the private sector. Based on our survey of 22 standards for open data, approximately half (12) clearly had broad stakeholder engagement. Seven were not considered multi-stakeholder; for three we were unsure about the extent of stakeholder engagement. We find the results encouraging because standards are effective and sustainable only if there is sufficient multi-party investment (Russell, 2014). Antrium (2017) observed that successful proposals to modify the GTFS standard "are most often led by someone with strong stake in the outcome (i.e. they represent the interests of a GTFS producer or consumer)".

Stakeholders benefit from standards that appear "authoritative, objective, uncontroversial, and natural" (Russell, 2014). This description suggests full agreement about standards; however committees and working groups are typically riddled with conflicting interests and are not necessarily attuned to all needs or preferences. Successfully adopted standards implies an ongoing dialogue between producers and consumers of open data that is consensus-based. A consensus of stakeholders protects against any authorities that intend to control, censor, or ignore alternate voices and perspectives (Russell, 2014). Consensus-based governance does not mean that all inputs are accepted if the majority agrees, but instead indicates a process in which creators of a standard are willing to address any request pertaining to the standard's statement of purpose.

We operationalized consensus-based governance for open data as any documentation of a deliberative process of development and/or maintenance, the presence of a governance charter, a github repository to file issues and commit source code, the presence of a mailing list, or centralized online location to post meeting minutes. Of note, five of the 22 open data standards were created from consensus procedures set by Standards Setting Organizations (SSOs). These standards bodies typically require a fee or a high level of technical expertise for membership. If we look for processes that offer mechanisms for end users feedback then we find seven additional standards. Mechanisms for end users to submit input about the standard include open mailing lists, comment/discussion lists, google groups, and github issues trackers. Sutor (2011) argues that a standard actually become increasingly open the more the "community", which also includes end users, can be involved. We argue that the creation of an open data standard cannot just be agreement. It also must encompass who is adequately represented during the agreement process. 
Table 6. Openness of process metrics for open data standards

\begin{tabular}{|c|c|c|c|}
\hline $\begin{array}{l}\text { Openness } \\
\text { Characteristics }\end{array}$ & Description & Value Type & Sources \\
\hline $\begin{array}{l}\text { Multi-Stakeholder } \\
\text { Participation }\end{array}$ & $\begin{array}{l}\text { Includes all parties to the } \\
\text { development of the standards. } \\
\text { Includes actual and anticipated } \\
\text { users as well as content } \\
\text { creators (i.e., domain experts) } \\
\text { and end users. }\end{array}$ & $\begin{array}{l}\text { "Yes"/ "No"/ } \\
\text { "Unsure" ; } \\
\text { Rationale }\end{array}$ & Russell, 2014 \\
\hline $\begin{array}{l}\text { Consensus-Based } \\
\text { Governance }\end{array}$ & $\begin{array}{l}\text { Reflects a process that allows } \\
\text { for critique and concerns } \\
\text { associated with the standard's } \\
\text { development and evolution. }\end{array}$ & $\begin{array}{l}\text { "Yes"/ "No" } \\
\text { / "Unsure"; } \\
\text { Rationale }\end{array}$ & Russell, 2014 \\
\hline $\begin{array}{l}\text { License Information } \\
\text { for the Standard }\end{array}$ & $\begin{array}{l}\text { Provides for information about } \\
\text { intellectual property rights of } \\
\text { the standard itself. }\end{array}$ & $\begin{array}{l}\text { License } \\
\text { name }\end{array}$ & $\begin{array}{l}\text { http://zenodo.org/record/1622 } \\
\text { 41\#.WWZNkf_yv5s }\end{array}$ \\
\hline
\end{tabular}

Open data by definition should be absent any legal restrictions on who and how the data can be used. The same cannot be said for the standard itself. Numerous types of intellectual property licenses could apply to standards (e.g., Creative Commons-Attribution license, version 4.0, Open Government License, BSD 3-clause "New" or "Revised" License). Attributes include open for anyone, regardless of use; open for non-commercial/public sector purposes only; open but one must credit the standards body; open but a "fork" is disallowed (i.e., any extensions must be incorporated into the original specification). For example, ISO requires a fee to access documentation about some of their information technology standards and publishes them under a single user license (e.g., ISO/IEC 20802-1:2016). We initially followed the guidelines (https://opensource.org/licenses) in our choice of standards that appeared to minimize restrictions on the standard's use and access as well as being standards that can be applied to open datasets. Of the 22 standards we evaluated, nine did not specify whether they publish a license for their standards. Of the thirteen that did specify a license, nine used some version of creative commons. These findings suggest that the majority of observed standards minimize restrictions and maximize repurposing and extending standards.

\section{Conclusion}

As governments apply open data standards to increase transparency and interoperability and improve data quality, they have good reasons to be confused. Their understanding is key: "What is, or is not included in a standard ... can result in significant political and social impacts" (Davies, Perini, \& Alonso, 2013, p. 14). The open data portal firm, Socrata (nd) asserts that choosing a standard represents an artform more than a science because standardization requires significant 
championing from senior staff as well as technical resources for adaptation of existing organizational practices. Add to this the variability within and among cities and this lends support to the XKCD cartoon (Figure 1). In government, most open data standards are geared towards the technical needs of developers (Goëta \& Davies, 2016). In this framework we try to bring standards out of a purely technical discourse and also emphasize the organizational (e.g., openness of standards development, level of adoption) and legal aspects of a very human process.

We developed a framework of 18 metrics to assess 22 existing civic open data standards. Standards fared best in denoting their maintenance, with dates of last updates and versions. Within a category, however, there is considerable variability. Interoperability exhibits the most intradimensional variability. In our examination, standards development tends to stress data exchange more than human readability. This reveals the existence of a narrow definition of interoperability and suggests that the primary interest for development lies with technicians and with content that can easily be quantified. At minimum, we hope this paper serves as a guide for developers to be more explicit, for example, about how open and extensible the process. A robust way of conceptualizing standards' development will round out the "readme" files to offer more than technical documentation.

This project continues to evolve with increasing numbers of standards. Future work includes expanding to more municipalities, including more high-value datasets, and investigating emerging standards. Open data standards for government, which are mindful of organizational needs, should serve the public good. Palfrey and Gasser (2012, p.3) remind us that,

More often than not, our future success in addressing the big societal challenges of our time, from healthcare to climate change, will depend heavily on our ability to create better interfaces and connections among complex systems and our ability to share information appropriately.

Acknowledgements: We are grateful to REDACTED for supporting second author during the writing of the paper and to REDACTED for now hosting the standards site and committing to maintain the standards.

Funding: This work was supported by REDACTED.

\section{References}

Aalders, H., \& Hunter, G. (2009). Spatial Data Standards. Advanced Geographic Information Systems. Encyclopedia of Life Support Systems. Paris: UNESCO.

Antrim, A. (2017). Life and growth of transport data standards - Lessons from 12 Years of GTFS. Trillium Solutions. https://trilliumtransit.com/2017/12/31/life-of-data-standards/\#7 Accessed 4 July 2018. 
Antrium, S., \& Barbeau, A. (2013). The many uses of GTFS data-opening the door to transit and multimodal applications. Paper presented at Intelligent Transportation Society (ITS) America's 23rd Annual Meeting and Exposition Nashville, TN.

Bennett, D., \& Harvey, A. (2009). Publishing open government data. https://www.w3.org/TR/govdata/ Accessed 4 July 2018.

Berners-Lee, T. (2010). Design issues: linked data. http://www.w3.org/DesignIssues/LinkedData.html. Accessed 4 July 2018.

Bruce, T. R. and Hillmann, D. I. (2004). The Continuum of metadata quality: Defining, expressing, exploiting. In D. I. Hillman \& E. L. Westbrooks (Eds.), Metadata in Practice (pp. 238-256). Chicago: American Library Association.

Butler, A., Hall, H., \& Copnell, B. (2016). A Guide to writing a qualitative systematic review protocol to enhance evidence-based practice in nursing and health care. Worldviews on Evidencebased Nursing, 13(3), 241-249.

Currie, L. (2013). The Role of Canadian municipal open data: A Multi-city evaluation. Masters Thesis. Kingston, Canada: Queen's University.

Davies, T. (2010). Open data, democracy and public sector reform - A Look at open government data use from data.gov.uk. Master Thesis. Oxford, United Kingdom: University of Oxford.

Davies, T., \& Perini, F. (2016). Researching the emerging impacts of open data: revisiting the ODDC conceptual framework. The Journal of Community Informatics, 12(2), 148-178.

Davies, T., Perini, F., \& Alonso, J. (2013). Researching the emerging impacts of open data: ODDC conceptual framework. Open Data in Developing Countries programme. London: World Wide Web Foundation.

Eaves, D. (2009). Three laws of open data. http://eaves.ca/2009/11/29/three-laws-of-open-datainternational-edition/ Accessed 4 July 2018.

Fox, M. S. (2013). City data: Big, open and linked. Technical Report, Enterprise Integration Lab, University of Toronto. http://www.eil.utoronto.ca/wp-content/uploads/smartcities/papers/CityData-v5.pdf Accessed 4 July 2018.

Geiger, C. P. \& von Lucke, J. (2012). Open government and (linked) (open) (government) (data). Journal of eDemocracy, 4(2), 265-278.

Goëta, S. \& Davies, T. (2016). The Daily shaping of state transparency: Standards, machinereadability and the configuration of open government data policies. Science and Technology Studies, 29(4), 10-30. 
Gonzalez Morales, L. \& Orrell, T. (2017). Multi-stakeholder meeting on data interoperability for the sustainable development goals. https:/undataforum.org/WorldDataForum/wpcontent/uploads/2017/04/Multi-stakeholder-Meeting-on-Data-Inter-operability.pdf Accessed 4 July 2018.

Government of Canada. (2016). Draft new plan on open government 2016-2018. http://open.canada.ca/en/consultations/canadas-new-plan-open-government-2016-2018 Accessed 4 July 2018.

Gurstein, M. B. (2011). Open data: Empowering the empowered or effective data use for everyone? First Monday, 16, 2.

Huijboom, N. \& Van den Broek, T. (2011). Open data: An International comparison of strategies. European Journal of ePractice, 12, 4-16.

Janssen, M., Charalabidis, Y., \& Zuiderwijk, A. (2012). Benefits, adoption barriers and myths of open data and open government. Information Systems Management, 29(4), 258-268.

Kitcat, J. (2004). Goverment [sic] and ICT standards: An Electronic voting case study. Information, Communication \& Ethics in Society, 2(1), 143-158.

Klein, M., \& Fensel, D. (2001). Ontology versioning on the semantic web. In I. F. Cruz (Ed.), Proceedings of the international semantic web working symposium (pp. 75-91). Arlington: National Science Foundation.

Klopp, J., Mutua, J., Orwa, D., Waiganjo, P., White, A., \& Williams, S. (2014). Towards a standard for paratransit data: Lessons from developing GTFS data for Nairobi's matatu system. Paper presented at the Transportation Research Board 93rd Annual Meeting, Washington, DC.

Krechmer, K. (2006). Open standards requirements. International Journal of IT Standards and Standardization Research, 4(1), 43-61.

Lampland, M., \& Star, S. L. (2008). Standards and their stories: How quantifying, classifying, and formalizing practices shape everyday life. Ithaca: Cornell University Press.

McHugh, B. (2013). Pioneering open data standards: The GTFS story. In B. Goldstein, with L. Dyson (Eds). Beyond transparency: Open data and the future of civic innovation (pp. 125-136). San Francisco: Code for America Press.

McKinney, J. \& Ashlock, P. (nd), Domain-specific standards project. https://docs.google.com/document/d/1ez3UXtBs_YpIZKEmmnDaeMHJ3oX3D0uahAdG8HKU_s w/edit Accessed 4 July 2018. 
Nalchigar, S., \& Fox, M.S. (2014). An Ontology for Open 311 data. Paper presented at the Workshop on Semantic Cities, Association for the Advancement of Artificial Intelligence, Québec City, Canada.

Nelson, M. L. (2003). The adoption and diffusion of interorganizational system standards and process innovations. Doctoral Dissertation. Champaign, USA: University of Illinois at UrbanaChampaign.

Ochoa, X., \& Duval, E. (2006). Quality metrics for learning object metadata. In E. Pearson, \& P. Bohman (Eds.), World Conference on Educational Multimedia, Hypermedia and Telecommunications 2006 (pp. 1004-1011). Orlando: Association for the Advancement of Computing in Education.

Offenhuber, D. (2015). Infrastructure legibility - a comparative analysis of open311-based citizen feedback systems. Cambridge Journal of Regions, Economy and Society, 8(1), 93-112.

Open Data Charter. (2015). International Open Data Charter. https://opendatacharter.net/wpcontent/uploads/2015/10/opendatacharter-charter_F.pdf Accessed 4 July 2018.

Open Knowledge Foundation. (nd). Open definition 2.1. Opendefinition.org. https://opendefinition.org/od/2.1/en/ Accessed 4 July 2018.

Ortega, A., Lopez-Briz, E., \& Fraga-Fuentes, M.D. (2016). From qualitative reviews to umbrella reviews. Chapter 3. In G. Biondi-Zoccai (Ed.), Umbrella Reviews: Evidence Synthesis with Overviews of Reviews and Meta-Epidemiological Studies (pp. 21-42). Dordrecht: Springer.

Palfrey, J.G., \& Gasser, U. (2012). Interop: The Promise and perils of highly interconnected systems. New York: Basic Books.

Piotrowski, S. J. \& Borry, E. (2010). An Analytic framework for open meetings and transparency. Public Administration and Management, 15(1), 138-176.

Poore, B. (2010). WALL-E and the "many, many" maps: Toward user-centred ontologies for The National Map. Cartographica: The International Journal for Geographic Information and Geovisualization, 45(2), 113-120.

Public Health Standards Consortium. (nd). Health information technology standards: Data standards. General Information about the Public Health Data Standards Consortium. http://www.phdsc.org/standards/health-information/D_Standards.asp Accessed 4 July 2018.

Raemaekers, S., Van Deursen, A., \& Visser, J. (2014). Semantic versioning versus breaking changes: A Study of the maven repository. In Dawn Lawrie, A. Hindle, \&R. Oliveto (Eds.), IEEE 14th International Working Conference on Source Code Analysis and Manipulation (pp. 215-224). Los Alamitos: Conference Publishing Services. 
Reiche, K.J., \& Höfig, E. (2013). Implementation of metadata quality metrics and application on public government data. In C. Seceleanu \& K. Yoshida (Eds.), IEEE Computer Software and Applications Conference Workshops (pp. 236-241). Los Alamitos: Conference Publishing Services.

Robinson, D.G., Yu, H., Zeller, W., \& Felten, E. (2009). Government data and the invisible hand. Yale Journal of Law \& Technology, 11(1), 160-175.

Rogers, E. M. (2003). Diffusion of innovations (5th ed.). New York: Simon and Schuster.

Russell, A. L. (2014). Open Standards and the Digital Age. Cambridge: Cambridge University Press.

Shadbolt, N., O'Hara, K., Berners-Lee, T., Gibbins, N., Glaser, H., Hall, W. \& schraefel, m.c. (2012). Linked open government data: Lessons from Data.gov.uk. IEEE Intelligent Systems, 27(3), $16-24$.

Shapiro, C. \& Varian, H.R. (1999). The Art of standards wars. California Management Review, 41(2), 8-32.

Shueh, J. (2015). 9 Localities commit to open data standard for construction, building permits. Government Technology Magazine. http://www.govtech.com/data/9-Localities-Commit-to-OpenData-Standard-for-Construction-Building-Permits.html Accessed 4 July 2018.

Sieber, R. E. \& Johnson, P.A. (2015). Civic open data at a crossroads: Dominant models and current challenges. Government Information Quarterly, 32(3), 308-315.

Socrata. (nd). Playbook for joining a civic data standard.

https://docs.google.com/document/d/1r80_XqkT_mCJuuPTotPUdSVh_hLxQTwUOKlk5GbgZdo/ edit Accessed 4 July 2018.

Suri, M. V. (2013). From crowd-sourcing potholes to community policing: Applying interoperability theory to analyze the expansion of 'Open311'. Cambridge, USA: Berkman Center.

Sutor, R. (2011). Software standards, openness, and interoperability. In L. DeNardis (Ed.), Opening standards: The Global politics of interoperability (pp. 209-218). Cambridge: MIT Press.

Suszan, B. (2014). The SpotCrime open crime standard (SOCS). http://blog.spotcrime.com/2014/03/the-spotcrime-open-crime-data-standard.html Accessed 4 July 2018.

UK Cabinet Office. (2015). Policy paper. Open Standards principles. https://www.gov.uk/government/publications/open-standards-principles/open-standards-principle Accessed 4 July 2018. 
Vetrò, A., Canova, L., Torchiano, M., Orozco Minotas, C., Iemma, R., \& Morando, F. (2016). Open data quality measurement framework: Definition and application to open government data. Government Information Quarterly, 33(2), 325-337.

Zhang, J., Dawes, S.S., \& Sarkis, J. (2005). Exploring stakeholders' expectations of the benefits and barriers of e-government knowledge sharing. Journal of Enterprise Information Management, 18(5), 548-567.

Zhu, H. \& Wu, H.. (2011). Interoperability of data created using extensible data standards. Paper presented at sigIQ (Information Quality) pre-ICIS (International Conference on Information Systems) workshop, Shanghai, China.

Zuiderwijk, A., \& Janssen, M. (2014). Open data policies, their implementation and impact: A Framework for comparison. Government Information Quarterly, 31(1), 17-29. 